\title{
DAMPAK IDEOLOGI ORGANISASI TERHADAP KEBERADAAN KOLEKSI DI PERPUSTAKAAN UNIVERSITAS MUHAMMADIYAH YOGYAKARTA
}

\author{
Suryanto \\ Institut Agama Islam Negeri Salatiga \\ e-mail: Suryanto@iainsalatiga.ac.id
}

\begin{abstract}
Abstrak:
Perpustakaan dapat dipahami sebagai situs ideologis. Perpustakaan UMY (Universitas Muhammadiyah Yogyakarta) merupakan lembaga yang berada di bawah naungan organisasi keagamaan Muhammadiyah. Sehingga setiap keputusan pemimpin akan berdampak pada keberadaan koleksi. Penelitian ini menggunakan metode penelitian studi literature terhadap konsep keilmuan bidang perpustakaan dan informasi. Studi literatur atau studi pustaka yang terkait dalam kajian layanan perpustakaan dan menganalisis beberapa koleksi yang ditemukan menggunakan kata kunci tertentu pada OPAC. Kata kunci yang digunakan adalah "muhammadiyah", "nahdatul ulama", "salafi", dan "hizbut tahrir". Data diperoleh dari hasil penelusuran koleksi pada OPAC menggunakan kata kunci tertentu. Data diolah dan disajikan secara deskriptif. Hasil dari penelitian menunjukkan bahwa dari keberadaan muhammadiyah corner yang menunjukkan bahwa koleksi yang ada merupakan koleksi yang berhubungan dengan ke-muhammadiyah-an. Jumlah Judul koleksi dengan kata kunci "muhammadiyah" yang memiliki perbandingan sebanyak 98,37\%. Begitu juga dengan penambahan koleksi dari tanggal 16 Desember 2016 sampai 17 November 2020 yang menunjukkan bahwa judul koleksi dengan kata kunci "muhammadiyah" bertambah sebanyak 311 judul. Hal tersebut menunjukkan bahwa Ideologi organisasi, dalam hal ini Muhammadiyah, ternyata memberikan dampak terhadap keberadaan koleksi di perpustakaan UMY.
\end{abstract}

Kata kunci: Ideologi; Muhammadiyah; Perpustakaan UMY; Koleksi Perpustakaan

\begin{abstract}
:
Libraries can be understood as ideological sites. UMY Library is an institution under the auspices of Muhammadiyah religious organization. So, every leader's decision will have an impact on the existence of the collection. This study uses a literature study research method on library and information science. Literature stud related to library service studies and analyze several collections found using certain keywords in the OPAC. The keywords used are "muhammadiyah", "nahdatul ulama", "salafi", and "hizbut tahrir". The data is obtained from the results of a collection search on the OPAC using certain keywords. The data is analized and presented descriptively. The result of the research shows that the existence of Muhammadiyah Corner shows that the existing collection is a collection related to Muhammadiyah's. The number of collection titles with the keyword "Muhammadiyah" which has a ratio of $98.37 \%$. Likewise with the addition of collections from 16 December 2016 to 17 November 2020 which shows that the title of the collection with the keyword "Muhammadiyah" has increased by 311 titles. This shows that the ideology of the organization, in this case Muhammadiyah, has an impact on the existence of collections in the UMY library.
\end{abstract}

Keywords: ideology; Muhammadiyah; UMY Library; Library collection

\section{Pendahuluan}

Suatu organisasi yang baik dan bisa berjalan dengan lancar salah satunya memiliki seorang pemimpin yang mampu memimpin suatu organisasi. Pemimpin memiliki peran yang sangat penting dalam menggerakkan para staf atau anggota organisasi. Mereka akan melakukan setiap keputusan yang telah diputuskan oleh pemimpin mereka. Hasilnya akan sangat berpengaruh pada warna dan keadaan organisasi yang dipimpin tersebut.

Dalam suatu perpustakaan, empat komponen yaitu tempat, manusia, aktivitas dan koleksi yang secara bersamaan membentuk suatu organisasi 


\section{Pendahuluan}

Suatu organisasi yang baik dan bisa berjalan dengan lancar salah satunya memiliki seorang pemimpin yang mampu memimpin suatu organisasi. Pemimpin memiliki peran yang sangat penting dalam menggerakkan para staf atau anggota organisasi. Mereka akan melakukan setiap keputusan yang telah diputuskan oleh pemimpin mereka. Hasilnya akan sangat berpengaruh pada warna dan keadaan organisasi yang dipimpin tersebut.

Dalam suatu perpustakaan, empat komponen yaitu tempat, manusia, aktivitas dan koleksi yang secara bersamaan membentuk suatu organisasi perpustakaan dan kemudian bertanggungjawab untuk mencapai suatu visi. Dalam upaya pencapaian visi di suatu organisasi, perpustakaan melakukan dengan melalui penyediaan akses informasi yang terbuka yang kemudian akan menghasilkan suatu pelayanan prima perpustakaan. Namun visi suatu organisasi sulit terlepas dari suatu praktik wacana kekuasaan sehingga kehadiran perpustakaan harus dilihat sebagai suatu proses dari produk budaya yang aktif.

Di samping itu, Perpustakaan dapat dipahami sebagai situs ideologis ${ }^{1}$ yang memasukkan suatu pendidikan sebagai salah satu bagian dari aparatus ideologis. ${ }^{2}$ Salah satu wujud tersebut adalah perpustakaan yang merupakan komponen penting dalam sistem pendidikan secara umum. Bahwa kehadiran perpustakaan dalam sistem pendidikan secara langsung menempatkannya pada suatu fokus yang disebut situs aparatus ideologis yang kemudian menjadi wahana konflik dan perjuangan ideologis antaraktor dalam struktur kelembagaan perpustakaan sebagai salah satu

${ }^{1}$ Dwi Cahyo Prasetyo, "Ruang Alternatif Dalam Layanan Corner Di Perpustakaan Universitas Muhammadiyah Yogyakarta (UMY): Relasi Kuasa, Karakteristik \& Makna" (Yogyakarta, UIN Sunan Kalijaga, 2019), https://core. ac.uk/display/328901887?utm_source $=$ pdf\&utm_medium =banner\&utm campaign $=$ pdf-decoration-v1

${ }^{2}$ Saparudin, Ideologi Keagamaan dalam Pendidikan: Diseminasi dan Kontestasi pada Madrasah dan Sekolah Islam di Lombok (Onglam Books, 2017), https://repository.uinjkt.ac.id/dspace/handle/123456789/49415.

${ }^{3}$ Nurdin Laugu, Representasi Kuasa Dalam Pengelolaan Perpustakaan: Studi Kasus Pada Perpustakaan Perguruan Tinggi Islam Di Yogyakarta (Yogyakarta: Gapernus Press, 2015), 4. organisasi yang berkembang dalam bidang pendidikan, pengetahuan dan informasi.

Menurut pernyataan Foucault bahwa konsep ideologi merupakan istilah yang sama dengan konsep kekuasaan. Bahwa kekuasaan tidak terletak pada satu orang atau kelompok tertentu, tetapi berada dimana-mana. Dalam situasi inilah ideologi dalam kekuasaan menjadi sebuah kekuatan yang membentuk berbagai kelompok masyarakat yang masing-masing bergerak berdasarkan bentuk ideologi yang dimiliki untuk memenangkan kelompok ideologi. ${ }^{3}$ Kekuasaan ideologi akan berjalan dikalangan berbagai aktor perpustakaan. Konsep inilah yang akan membawa perpustakaan sebagai konsekuensi dari penjelmaan ideologi dalam ranah pengelolaan perpustakaan yang akan memberikan suatu gambaran bahwa pengelolaan perpustakaan akan melakukan suatu proses yang mendukung. Hal inilah yang dilakukan perpustakaan sebagai produk budaya dan situs ideologi yang mengalami proses dinamis dalam hampir setiap aktivitas yang dilakukannya

Salah satu Perpustakaan Perguruan Tinggi Islam di Yogyakarta yaitu perpustakaan Universitas Muhammadiyah Yogyakarta (Selanjutnya disebut UMY) yang merupakan salah satu unit pelaksanaan teknis yang bersama-sama dengan unit lainnya mendukung pencapaian visi dan misi perguruan tinggi UMY sebagai lembaga pendidikan dan pengetahuan untuk masyarakat, khususnya masyarakat islam. Sebagai budaya, perpustakaan mengalami perkembangan pesat dalam merespon arus informasi dan pengetahuan yang diproduksi secara tidak terbatas yang sering disebut sebagai ledakan informasi. Sebagai budaya UMY akan mengalami suatu perkembangan dan perubahan

${ }^{4} \mathrm{R}$. K. Bhatt, "Relevance of Ranganathan's Laws of Library Science in Library Marketing," Library Philosophy and Practice, July 1, 2011, https:// go.gale.com/ps/i.do?p $=$ AONE\&sw $=w \& i s s n=15220222 \& v=2.1 \& i t=r \&$ id=GALE\%7CA267422512\&sid=googleScholar\&linkaccess=abs; Moh Safii, "Redefining The Five Laws of Library Science in the Digital Age" (2nd Internasional Conference on Culture and Language in Southeast Asia (ICCLAS 2018), Atlantis Press, 2019), 24-27, https://doi.org/10.2991/icclas-18 .2019.7.

${ }^{5}$ Laugu, Representasi Kuasa Dalam Pengelolaan Perpustakaan: Studi Kasus Pada Perpustakaan Perguruan Tinggi Islam Di Yogyakarta, 111. 
seiring dengan perkembangan dan perubahan masyarakat dalam ruang dan waktu yang berbeda. ${ }^{4}$ Untuk mewujudkan perpustakaan sebagai ruang belajar seumur hidup perpustakaan UMY menggunakan ungkapan seperti "We Bring Knowledge Closer to You" bahwasanya ungkapan ini dimaksudkan untuk orang-orang yang mencintai ilmu dan berilmu. ${ }^{5}$

Perpustakaan UMY merupakan lembaga yang berada di bawah naungan organisasi keagamaan Muhammadiyah. Sehingga setiap keputusan pemimpin akan berdampak pada keberadaan koleksi. Koleksi memiliki beberapa fungsi antara lain fungsi pendidikan yang menjadikan keberadaan koleksi harus sesuai dengan ideologi organisasi agar pendidikan yang dibangun di UMY mampu menjaga ideologi tersebut. Keputusan ketika melakukan pengadaan akan mempertimbangkan visi dari indeologi lembaga induk yaitu Muhammadiyah.

\section{Tinjauan Pustaka \\ Ideologi}

Ideologi berasal dari bahasa Greek, yang terdiri dari kata idea dan logia. Idea berasal dari kata idean yang berarti melihat. Idea dalam buku The Advence Learner's Dictionary berarti a plan or schema formed in the mind atau suatu rencana yang dibentuk/ durumuskan didalam pemikiran. Logis berasal dari kata logos yang berarti word dimana kata ini berasal dari kata legein yang berarti to speak adalah berbicara. Selanjutnya kata logia berarti science (pengetahuan) atau theory. Jadi ideologi menurut arti kata ialah pengucapan dari pada yang terlihat atau pengutaraan apa yang terumus di dalam pikiran sebagai hasil dari pada pemikiran. ${ }^{6}$

Ideologi juga bisa dikatakan sebagai konsep

${ }^{6}$ Firdha Junita and Mulharnetti Syas, "Perbandingan Frame Berita Tentang Kasus Korupsi Proyek Pengadaan KTP Elektronik Antara Suratkabar Kompas Dan Koran Tempo," Prosiding Konferensi Nasional Komunikasi 1 , no. 01 (2017); Moh Suardi, Ideologi Politik Pendidikan Kontemporer (Yogyakarta: Deepublish, 2015)

${ }^{7}$ Terry Eagleton, Ideology (London and New York: Routledge, 2014).

${ }^{8}$ Laugu, Representasi Kuasa Dalam Pengelolaan Perpustakaan: Studi Kasus Pada Perpustakaan Perguruan Tinggi Islam Di Yogyakarta, 115. klasik yang selalu aktif dan dinamis dalam perkembangan masyarakat di berbagai ruang dan waktu. Banyak ahli dan teoretisi terlibat dalam upaya menafsirkan konsep tersebut. Terry Eangleton mengemukakan bahwa ideologi memiliki pengertian yang beragam dan tidak dapat disatukan. ${ }^{7}$ Salah satunya bahwa tidak semua formulasi ideologi cocok antara satu dan lainnya sehingga masing-masing definisi dipegangi oleh kelompok yang cocok dengannya. Di samping itu, formulasi ideologi ada yang bersifat pejoratif dan ada yang tidak sebagaimana di satu sisi definisi ideologi yang melibatkan pernyataan epistemologis dan tidak di sisi lainnya.

\section{Paham Keagamaan (Muhammadiyah)}

Secara umum paham keagamaan pada aktor perpustakaan UMY tidak dilakukan dengan terang-terangan adanya pertarungan ideologi keagamaan. Hal ini terlihat pada perilaku persaingan ideologi keagamaan yang dihindari oleh para pengelola perpustakaan. Alasan ini karena dengan adanya paham keagamaan nantinya tidak akan menghasilkan sebuah prestasi dan profesionalitas yang bisa mengangkat bisnis utama perpustakaan. Bahwasanya visi dan misi perpustakaan harus bersifat pluralis dalam tolak ukur yang harus dikembangkan sebagai kompetensi professional dan social antara mereka yang mana nantinya pengelolaan perpustakaan bisa mencapai tingkat pelayanan yang diinginkan. ${ }^{8}$ Bahwa kehadiran unsur keagamaan dalam konteks ini telah menjadi suatu basis petimbangan kompetensi spiritual mereka untuk menjadi pustakawan yang religious. Paham keagamaan sebagai saluran ideologi terlihat berbasis pada lembaga induk, yaitu perguruan tinggi yang mewadahi perpusta-

${ }^{9}$ Departemen Pendidikan Nasional, Kamus Besar Bahasa Indonesia Pusat Bahasa (Jakarta: Gramedia Pustaka Utama, 2013), 693.

${ }^{10}$ Ludya Arica Bakti, "Penyebaran Informasi Koleksi Perpustakaan Melalui Media Sosial," ACARYA PUSTAKA: Jurnal Ilmiah Perpustakaan dan Informasi 7, no. 1 (September 28, 2020): 40-49, https://doi.org/10.23887/ ap.v7i1.21898; Lisa Noviani Maghfiroh, "Pengadaan Koleksi Bahan Pustaka Tercetak UPT Perpustakaan Universitas Janabadra Yogyakarta," Jurnal Pustaka Ilmiah 3, no. 2 (August 22, 2019): 467-74, https://doi.org/10.20961/ jpi.v3i2.34131. 
kaan. hubungan dan petarungan ideologi terlihat jelas pada hubungan politik.

\section{Khitah Organisasi}

Khitah berarti tujuan dasar; garis haluan; landasan perjuangan; atau kebijakan. ${ }^{9}$ Khitah organisasi dapat diartikan garis halauan suatu organisasi. Dalam Muhammadiyah, khitah menjadi pedoman yang dipegang oleh Muhammadiyah yang sangat berguna ketika menghadapi kenyataan yang sebenarnya di masyarakat. Khitah akan menjadi landasan berpikir dan amal usaha bagi semua pimpinan dan anggota Muhammadiyah.

Namun, Khitah dapat dipahami sebagai salah satu faktor yang memberikan kontirbusi terhadap kelambatan atau bahkan stagnasi dalam pengembangan SDM, termasuk perpustakaan UMY, bila dibandingkan dengan pengembangan SDM perpustakaan lainnya yang lebih maju. Hal ini dapat menjadikan adanya pengabaian kompetensi profesionalitas seseorang calon pegawai perpustakaan akibat dari tradisi rekruitmen. Orangorang Muhammadiyah mempunyai komitmen dalam kemuhammadiyahannya karena mereka mengalami pengkaderan yang panjang, khususnya memperhatikan kehidupan muhammadiyah bukan untuk mencari hidup di muhammadiyah. Hal ini lah yang memperkuat implementasi khitah yang mengabaikan kompetensi profesionalitas tapi juga objektivitas penerapan di kalangan organisasi tersebut secara umum.

\section{Koleksi Perpustakaan}

Koleksi merupakan salah satu unsur pokok yang harus ada di perpustakaan. Koleksi merupakan inti dari perpustakaan, koleksi tersebut diolah dan dilayankan kepada penguna prpusta-

\footnotetext{
${ }^{11}$ Departemen Pendidikan dan Kebudayaan, Buku Pedoman Perpustakaan Perguruan Tinggi (Jakarta: Departemen Pendidikan dan Kebudayaan, 2004).

${ }^{12}$ Imran Benawi, "Mengenal lebih dekat perpustakaan perguruan tinggi," Iqra': Jurnal Perpustakaan dan Informasi 06, no. 01 (May 15, 2012): 49-61.
}

kaan. perpustakaan dapat dinilai baik atau tidak dengan mengetahui tingkat pemanfaatan koleksi yang ada di perpustakaan tersebut.

Koleksi adalah sekumpulan rekaman informasi dalam berbagai bentuk tercetak (buku, majalah, surat kabar) dan bentuk tidak tercetak (bentuk mikro, bahan audio visual, peta). ${ }^{10}$ Koleksi memiliki beberapa fungsi yaitu pertama, fungsi pendidikan. Koleksi perpustakaan berfungsi untuk menunjang program pendidikan dan pengajaran, perpustakaan mengadakan bahan pustaka yang sesuai atau relevan dengan jenis dan tingkat program yang ada. Kedua, fungsi penelitian. Koleksi perpustakaan berfungsi untuk menunjang program penelitian perguruan tinggi, perpustakaan menyediakan sumber informasi tentang berbagai hasil penelitian dan kemajuan ilmu pengetahuan mutakhir. Ketiga, fungsi referensi. Fungsi ini melengkapi fungsi yang di atas dengan menyediakan bahan bahan referensi dari berbagai bidang dan alat-alat bibliografis yang diperlukan untuk menelusur informasi. Keempat, fungsi umum. Perpustakaan perguruan tinggi juga merupakan pusat informasi bagi masyarakat disekitarnya, fungsi ini berhubungan dengan program pengabdian masyarakat dan pelestarian bahan pustaka serta hasil budaya manusia yang lain. ${ }^{11}$

Koleksi perpustakaan juga memiliki beberapa jenis, yaitu: 1) Buku merupakan koleksi yang paling umum dihimpun oleh perpustakaan. Yang termasuk kedalam jenis buku yaitu buku teks, buku penunjang, buku-buku jenis fiksi serta buku bergambar dan buku populer yang berisi pengetahuan umum dan populer. 2) Koleksi referensi. Isi buku referensi tidak mendalam dan kadangkadang hanya memuat informasi tertentu saja.

${ }^{13}$ Dewi Surani, "Studi Literatur: Peran Teknolog Pendidikan Dalam Pendidikan 4.0," Prosiding Seminar Nasional Pendidikan FKIP 2, no. 1 (May 31, 2019): 456-69; Nur Riani, "Model Perilaku Pencarian Informasi Guna Memenuhi Kebutuhan Informasi (Studi Literatur)," Publication Library and Information Science 1, no. 2 (November 30, 2017): 14-20, https://doi.org/10.24269/pls.v1i2.693; Suryanto Suryanto, Nurul Setyawati Handayani, and Nur Riani, "Mengadopsi Layanan McDonald's Sebagai Alternatif Layanan Perpustakaan Di Masa Pandemi Covid-19," Pustabiblia: Journal of Library and Information Science 4, no. 2 (December 7, 2020): 225-44, https://doi.org/10.18326/pustabiblia.v4i2.225-244. 
Contoh: kamus, ensiklopedia, almanak, direktori dan buku tahunan. 3) Sumber geografi. Jenis koleksi ini berisi informasi tentang, hutan, daerah, iklim, cuaca, ketinggian tempat, bahan tambang, hasil pertanian daerah tertentu, laut, gunung, gurun dan lainnya. Bentuk sumber geografi pada umumnya adalah peta, atlas, globe. 4) Jenis serial (terbitan berkala). Pada umumnya terbitan berkala berupa majalah dan koran yang diperlukan sebagai koleksi perpustakaan karena keduanya berisi berita aktual yang meliputi berbagai aspek kehidupan manusia. 5) Bahan mikro merupakan koleksi perpustakaan yang merupakan alih media dari buku kedalm bentuk mikro seperti mikrofilm dan mikrofice. 6) Audio Visual merupakan koleksi perpustakaan yang memuat informasi yang dapat ditangkap secara bersamaan oleh indra mata dan telinga. Contoh: video, kaset, peringan hitam, VCD, slide dan film. ${ }^{12}$

\section{Metode Penelitian}

Metode yang digunakan dalam penelitian ini adalah studi literature terhadap konsep keilmuan bidang perpustakaan dan informasi. ${ }^{13}$ Studi literatur atau studi pustaka yang terkait dalam kajian layanan perpustakaan dan menganalisis beberapa koleksi yang ditemukan menggunakan kata kunci tertentu pada OPAC. Data diperoleh dari hasil penelusuran koleksi pada OPAC menggunakan kata kunci tertentu. Data diolah dan disajikan secara deskriptif.

\section{Hasil dan Pembahasan \\ Muhammadiyah Corner}

Muhammadiyah corner merupakan salah satu layanan perpustakaan pusat UMY yang menyediakan koleksi koleksi terkait ke-muhammadiyahan. Keberadaan muhammadiyah corner digunakan bagi yang tertarik untuk meneliti Muhammadi-

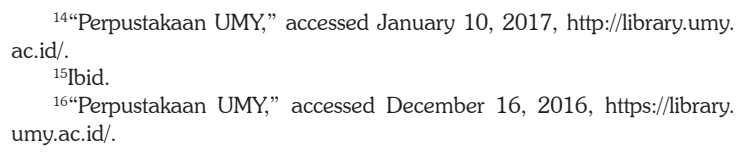

yah. Selain koleksi ke-muhammadiyahan, di dalamnya juga menyimpan kitab-kitab salaf, diantaranya tafsir ibnu katsir, fikih al-um, dan lain sebagainya. Muhammadiyah corner terletak di Gedung D lantai 3, berada di sebelah utara perpustakaan pusat UMY. ${ }^{14}$

Keberadaan muhammadiyah corner menjadi salah satu bukti bahwa ideologi muhammadiyah sangat berperan dalam pengembangan koleksi di perpustakaan UMY. Muhammadiyah corner yang menyediakan koleksi tentang ke-muhammadiyah-an tidak terlepas dari khitah organisasi yang menjadi induk dari perpustakaan UMY yaitu Muhammadiyah.

\section{Tipe Koleksi}

Berdasarkan tipe koleksinya, perpustakaan UMY membagi tipe koleksi menjadi 20 buah. Berikut ini adalah rekapitulasi jumlah koleksi yang dimiliki perpustakaan UMY berdasarkan tipe koleksi, yaitu ${ }^{15}$

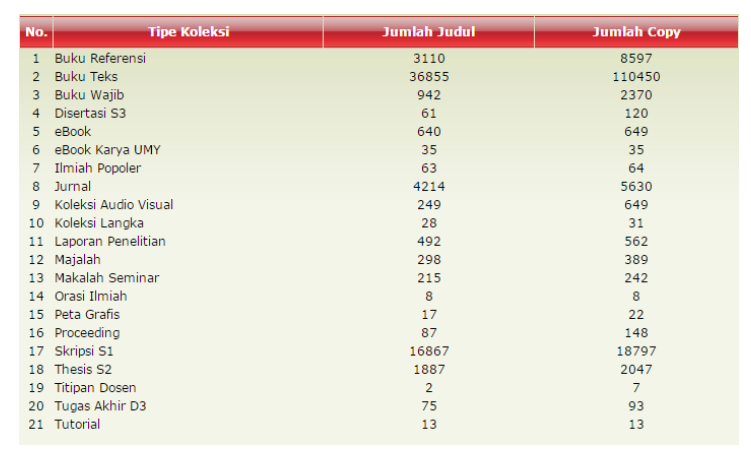

Gambar 1. Tipe Koleksi Perpustakaan UMY

Berdasarkan dari data gambar 1 terlihat bahwa koleksi buku teks merupakan koleksi yang paling banyak dimiliki oleh perpustakaan UMY. Hal ini menandakan bahwa fokus pengadaan koleksi di perpustakaan UMY berupa buku teks.

\section{Jumlah Judul Koleksi}

Keberadaan koleksi di perpustakaan sebagai

\footnotetext{
17"Perpustakaan UMY," accessed November 17, 2020, https://ibrary. umy.ac.id/,

${ }^{18}$ Data tanggal 17 November 2020
} 
bentuk gambaran ideologi dari perpustakaan tersebut. Begitu juga dengan perpustakaan UMY yang perbandingan buku berjudul muhammadiyah lebih banyak dari pada keberadaan buku berjudul dengan ideologi selain muhammadiyah.

Penelusuran dilakukan pada halaman OPAC Perpustakaan UMY ${ }^{16}$ pada tanggal 16 Desember 2016 dengan kata kunci "muhammadiyah", "nahdatul ulama", "salafi", dan "hizbut tahrir". Total hasil penelusuran dengan empat kata kunci tersebut ditemukan sebanyak 2571 judul.

Hasil untuk penelusuran dengan kata kunci "muhammadiyah" ditemukan ada 2528 judul (98,32\%). Penelusuran dengan menggunakan kata kunci "nahdatul ulama" hanya ditemukan 3 judul (0,12\%). Penggunaan kata kunci "salafi" ditemukan 29 judul (1,13\%). Sedangkan penelusuran menggunakan kata kunci "hizbut tahrir" ditemukan 11 judul $(0,43 \%)$.

Pada tanggal 10 Januari 2017, penelusuran kembali menggunakan empat (4) kata kunci tersebut. Penelusuran menggunakan kata kunci "muhammadiyah" ditemukan sebanyak 2536 judul (98,33\%). Penelusuran menggunakan kata kunci "nahdatul ulama" ditemukan sebanyak 3 judul $(0,12 \%)$. Penelusuran menggunakan kata kunci "salafi" ditemukan sebanyak 29 judul $(1,12 \%)$. Sedangkan penelusuran menggunakan kata kunci "hizbut tahrir" ditemukan sebanyak 11 judul (0,43\%).

Kemudian pada tanggal 17 November 2020 , penelusuran kembali dilakukan menggunakan empat (4) kata kunci yang sama. Penelusuran menggunakan kata kunci "muhammadiyah" ditemukan sebanyak 2841 judul (98,37\%). Penelusuran menggunakan kata kunci "nahdatul ulama" ditemukan sebanyak 4 judul (0,14\%). Penelusuran menggunakan kata kunci "salafi" ditemukan sebanyak 30 judul (1,04\%). Sedangkan penelusuran menggunakan kata kunci "hizbut tahrir" ditemukan sebanyak 113 judul $(0,45 \%) .{ }^{17}$
Tabel 1. Jumlah koleksi berdasarkan kata kunci

\begin{tabular}{|c|c|c|c|c|c|}
\hline \multirow{2}{*}{ Tanggal } & \multicolumn{4}{|c|}{ Kata Kunci (Judul) } & \multirow{2}{*}{ Total } \\
\cline { 2 - 5 } & Muhammadiyah & $\begin{array}{c}\text { Nahdatul } \\
\text { Ulama }\end{array}$ & Salafi & $\begin{array}{c}\text { Hizbut } \\
\text { Tahrir }\end{array}$ & \\
\hline $\begin{array}{c}16 \\
\text { Desember } \\
2016\end{array}$ & $2528(98,32 \%)$ & $\begin{array}{c}3 \\
(0,12 \%)\end{array}$ & $\begin{array}{c}29 \\
(1,13 \%)\end{array}$ & $\begin{array}{c}11 \\
(0,43 \%)\end{array}$ & $\begin{array}{c}2571 \\
(100 \%)\end{array}$ \\
\hline $\begin{array}{c}10 \text { Januari } \\
2017\end{array}$ & $2536(98,33 \%)$ & $\begin{array}{c}3 \\
(0,12 \%)\end{array}$ & $\begin{array}{c}29 \\
(1,12 \%)\end{array}$ & $\begin{array}{c}11 \\
(0,43 \%)\end{array}$ & $\begin{array}{c}2579 \\
(100 \%)\end{array}$ \\
\hline $\begin{array}{c}17 \\
\text { November } \\
2020\end{array}$ & $2841(98,37 \%)$ & $\begin{array}{c}4 \\
(0,14 \%)\end{array}$ & $\begin{array}{c}30 \\
(1,04 \%)\end{array}$ & $\begin{array}{c}13 \\
(0,45 \%)\end{array}$ & $\begin{array}{c}2888 \\
(100 \%)\end{array}$ \\
\hline
\end{tabular}

Hasil penelusuran tersebut menunjukkan bahwa khitah muhammadiyah sangat berpengaruh pada keberadaan koleksi perpustakaan. Perbandingan antara kata kunci "muhammadiyah" dengan ketiga kata kunci sangat besar. Bahkan persentase jumlah koleksi dengan kata kunci "muhammadiyah" mengalami peningkatan yaitu dari 98,32\% menjadi 92,33\% dan kemudian menjadi $98,37 \%$.

\section{Penambahan Koleksi}

Pada judul koleksi tersebut diatas yang dilakukan pada tanggal 16 Desember 2016 terlihat bahwa jumlah koleksi dengan kata kunci "muhammadiyah" memiliki jumlah yang paling banyak, bahkan mencapi $98,32 \%$ dibandingkan 3 kata kunci yang lain dan mengalami peningkatan persentase jumlah koleksi dari waktu ke waktu. Selanjutnya menghitung selisih jumlah koleksi dari waktu-waktu tertentu tersebut. Selisih jumlah koleksi menunjukkan jumlah penambahan buku pada judul dengan kata kunci tersebut.

Hasil untuk penelusuran koleksi pada tanggal 10 Januari 2017 dengan kata kunci "muhammadiyah" ditemukan sebanyak 2536 judul. Jumlah ini selisih 8 judul ketika dilakukan pada tanggal 16 Desember 2016. Namun ketika menelusur menggunakan ketiga kata kunci selain "muhammadiyah" tidak ditemukan penambahan judul.

Penelusuran kembali dengan kata kunci "muhammadiyah" pada tanggal 17 November 2020. Dari hasil penelusuran, ditemukan 2841 judul dengan kata kunci tersebut. Hal ini menunjukkan penambahan koleksi dengan kata kunci "muhammadiyah" dari tanggal 10 Januari 2017 sampai tanggal 17 November 2020 sebanyak 305 judul. 
Sedangkan untuk judul dengan kata kunci "nahdatul ulama", penelusuran yang dilakukan pada tanggal 17 November 2020 berjumlah 4 judul. Jumlah ini mengalami peningkatan 1 judul dari tanggal 16 Desember 2016.

Penelusuran menggunakan kata kunci "salafi" memperoleh hasil sebanyak 30 Judul. Jumlah tersebut naik sebanyak 1 judul dari tanggal 16 Desember 2017. Kemudian penelusuran menggunakan kaya kunci "hizbut tahrir" ditemukan 13 judul bertambah 2 judul dari tanggal 16 Desember 2016 .

Berdasarkan dari uraian di atas, dapat ditentukan total penambahan koleksi dari tanggal 16 Desember 2016 s.d. 17 November 2020 sebagai berikut.

1. Koleksi dengan kata kunci "muhammadiyah" mengalami penambahan koleksi sebanyak 311 judul.

2. Koleksi dengan kata kunci "nahdatul ulama" mengalami penambahan koleksi sebanyak 1 judul.

3. Koleksi dengan kata kunci "salafi" mengalami penambahan koleksi sebanyak 1 judul, dan

4. Koleksi dengan kata kunci "hizbut tahrir" mengalami penambahan sebanyak 2 judul.

Agar lebih mudah dalam memahami penambahan koleksi dari keempat kata kunci tersebut, berikut disajikan dalam tabel 2 .

Tabel 2. Penambahan koleksi dari waktu ke waktu

\begin{tabular}{|c|c|c|c|c|}
\hline \multirow{2}{*}{ Tanggal } & \multicolumn{4}{|c|}{ Penambahan(Judul) } \\
\cline { 2 - 5 } & Muhammadiyah & $\begin{array}{c}\text { Nahdatul } \\
\text { ulama }\end{array}$ & Salafi & $\begin{array}{c}\text { Hizbut } \\
\text { Tahrir }\end{array}$ \\
\hline $\begin{array}{c}\text { 16 Desember 2016- } \\
\text { 10 Januari 2017 }\end{array}$ & 6 & 0 & 0 & 0 \\
\hline $\begin{array}{c}\text { 10 Januari 2017- } \\
\text { 17 November 2020 }\end{array}$ & 305 & 1 & 1 & 2 \\
\hline $\begin{array}{c}\text { 16 Desember 2016- } \\
\text { 17 November 2020 }\end{array}$ & 311 & 1 & 1 & 2 \\
\hline
\end{tabular}

\section{Kesimpulan dan Saran}

Ideologi organisasi, dalam hal ini Muhammadiyah, ternyata memberikan dampak terhadap keberadaan koleksi di perpustakaan UMY. Dalam makalah ini ditemukan bahwa dampak itu dapat dilihat pada keberadaan koleksi dilihat dari keberadaan muhammadiyah corner yang menunjukkan bahwa koleksi yang ada merupakan koleksi yang berhubungan dengan ke-muhammadiyahan. Jumlah judul koleksi dengan kata kunci "muhammadiyah" yang memiliki perbandingan sebanyak $98,37 \%^{18}$ dari ketiga kata kunci yang lain juga menunjukkan dampak ideologi muhammadiyah dalam mempengaruhi keberadaan koleksi. Presentasi jumlah koleksi dengan kata kunci "muhammadiyah" yang terus naik juga menjadi bukti bahwa keberadaan koleksi dipengaruhi oleh ideology muhammadiyah. Begitu juga dengan penambahan koleksi dari tanggal 16 Desember 2016 sampai 17 November 2020 yang menunjukkan bahwa judul koleksi dengan kata kunci "muhammadiyah" bertambah sebanyak 311 judul sedangkan ketiga kata kunci yang lain bertambah masing-masing "nahdatul ulama" 1 judul, "salafi" 1 judul, dan "hizbut tahrir" 2 judul.

Saran untuk penelitian lanjutan bahwa perlu diadakan penelitian serupa di perpustakaan lain yang berada di bawah ideologi lain selain $\mathrm{Mu}-$ hammadiyah, seperti Nahdatul Ulama di UNU Jogja. Hal tersebut akan menjadi pembanding mengenai apakah di UNU Jogja ideologi Nahdatul Ulama memiliki pengaruh terhadap keberadaan koleksi perpustakaan.

\section{Referensi}

Bakti, L.A. (2020) Penyebaran Informasi Koleksi Perpustakaan Melalui Media Sosial. ACARYA PUSTAKA: Jurnal Ilmiah Perpustakaan dan Informasi, 7(1), 40-49. https://doi. org/10.23887/ap.v7i1.21898.

Benawi, I. (2012). Mengenal lebih dekat perpustakaan perguruan tinggi. Iqra': Jurnal Perpustakaan dan Informasi, 6(1), 49-61.

Bhatt, R. K. (2011). Relevance of Ranganathan's Laws of Library Science in Library Marketing. Library Philosophy and Practice, July 1 , 2011. https://go.gale.com/ps/i.do?p=AONE $\& s w=w \& i s s n=15220222 \& v=2.1 \& i t=r \& i d$ 
$=$ GALE $\% 7 C A 267422512 \&$ sid $=$ googleSch olar\&linkaccess $=$ abs.

Departemen Pendidikan dan Kebudayaan. (2004) Buku Pedoman Perpustakaan Perguruan Tinggi. Jakarta: Departemen Pendidikan dan Kebudayaan

Departemen Pendidikan Nasional. (2013). Kamus Besar Bahasa Indonesia Pusat Bahasa. Jakarta: Gramedia Pustaka Utama

Eagleton, T. (2014). Ideology. London and New York: Routledge

Junita, F, \& M. Syas, M. "Perbandingan Frame Berita Tentang Kasus Korupsi Proyek Pengadaan KTP Elektronik Antara Suratkabar Kompas Dan Koran Tempo." Prosiding Konferensi Nasional Komunikasi 1, no. 01 (2017).

Laugu, N. (2015). Representasi Kuasa Dalam Pengelolaan Perpustakaan: Studi Kasus pada Perpustakaan Perguruan Tinggi Islam di Yogyakarta. Yogyakarta: Gapernus Press

Maghfiroh, L.N. (2019). Pengadaan Koleksi Bahan Pustaka Tercetak UPT Perpustakaan Universitas Janabadra Yogyakarta. Jurnal Pustaka Ilmiah, 3(2), 467-474. https://doi. org/10.20961/jpi.v3i2.34131.

Perpustakaan UMY. Accessed January 10, 2017. http://ibrary.umy.ac.id/.

Perpustakaan UMY. Accessed December 16, 2016. https://library.umy.ac.id/.

Perpustakaan UMY. Accessed November 17, 2020. https://ibrary.umy.ac.id/.

Prasetyo, D.C. (2019). Ruang Alternatif Dalam Layanan Corner di Perpustakaan Univer- sitas Muhammadiyah Yogyakarta (UMY):

Relasi Kuasa, Karakteristik \& Makna. UIN Sunan Kalijaga, https://core.ac.uk/ display/328901887?utm_source $=$ pdf\&utm medium $=$ banner\&utm_campaign $=$ pdf-decoration-v1.

Riani, N. (2017). Model Perilaku Pencarian Informasi Guna Memenuhi Kebutuhan Informasi (Studi Literatur)." Publication Library and Information Science, 1(2), 14-20. https:// doi.org/10.24269/pls.v1i2.693.

Safii, M. (2019). Redefining The Five Laws of Library Science in the Digital Age, 24-27. Atlantis Press. https://doi.org/10.2991/icclas18.2019.7.

Saparudin. (2017). Ideologi Keagamaan dalam Pendidikan : Diseminasi dan Kontestasi pada Madrasah dan Sekolah Islam di Lombok. Onglam Books, 2017. https://repository.uinjkt.ac.id/dspace/handle/123456789/49415.

Suardi, M. (2015). Ideologi Politik Pendidikan Kontemporer. Yogyakarta: Deepublish

Surani, D. (2019). Studi Literatur : Peran Teknolog Pendidikan Dalam Pendidikan 4.0. Prosiding Seminar Nasional Pendidikan FKIP 2, no. 1 (May 31, 2019): 456-69.

Suryanto, S.; Handayani, N.S.; \& Riani, N.. (2020). Mengadopsi Layanan McDonald's Sebagai Alternatif Layanan Perpustakaan di Masa Pandemi Covid-19." Pustabiblia: Journal of Library and Information Science, 4(2), 225-44. https://doi.org/10.18326/pustabiblia.v4i2.225-244. 